\title{
Serum Vitamin D Levels and Risk Factors for Cardiovascular Complication in Diabetes
}

\author{
Rina Amelia ${ }^{1 *}$, Juliandi Harahap ${ }^{1}$, Hendri Wijaya ${ }^{2}$, Isti Ilmiati Fujiati ${ }^{1}$, Sry Suryani Widjaja ${ }^{3}$, Rusdiana Rusdiana ${ }^{3}$ \\ ${ }^{1}$ Department of Community Medicine and Public Health, Faculty of Medicine, Universitas Sumatera Utara, Medan, Indonesia; \\ ${ }^{2}$ Department of Pediatrics, Faculty of Medicine, Universitas Sumatera Utara, Medan, Indonesia; ${ }^{3}$ Department of Biochemistry, \\ Faculty of Medicine, Universitas Sumatera Utara, Medan, Indonesia
}

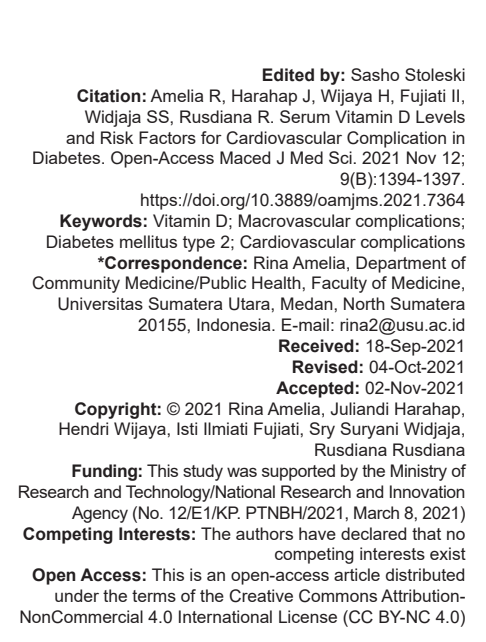

Abstract

BACKGROUND: Diabetes is a significant contributor to dyslipidemia, which can contribute in cardiovascular complications. Vitamin $\mathrm{D}$ is crucial in preventing chronic metabolic diseases such as diabetes and heart disease (cardiovascular disease [CVD])

AIM: The objective of this study was to determine the relationship between Vitamin D levels and cardiovascular risk in type 2 diabetes mellitus.

MATERIALS AND METHODS: This study is cross-sectional in nature. The study sampled 89 diabetic patients who met the study's inclusion and exclusion criteria. After a $10 \mathrm{~h}$ fast, a venous blood test is performed to determine Vitamin D levels, apolipoprotein-A levels, total cholesterol (TC), low-density lipoprotein cholesterol (LDL-C), highdensity lipoprotein cholesterol (HDL-C), and triglyceride levels. The data are analyzed using SPSS. The Pearson correlation test $(p>0.05)$ was used to determine the connection.

RESULT: Vitamin D levels were found to correlate with Apo-A1, TC, HDL-C, and triglyceride levels $(p=0.05)$, but not with LDL-C levels ( $p>0.05$ ).

CONCLUSION: Vitamin D supplementation may assist DMT2 patients minimize their chance of developing CVD problems.

\section{Introduction}

Dyslipidemia is a metabolic disease characterized by an increase in total cholesterol (TC) or triglyceride levels in the blood and a reduction in high-density lipoprotein cholesterol (HDL-C) levels [1]. Chronic hyperglycemia associated with diabetes alters the metabolism of cholesterol, triglycerides, and their highly controlled metabolites, resulting in hypercholesterolemia and hypertriglyceridemia [2].

Vitamin $D$ is a fat-soluble vitamin that is required for calcium homeostasis and bone growth. Vitamin $D$ receptors are found in a number of tissues and play critical roles in the production of insulin, immune function, gene expression, and cardiovascular protection [3]. In addition, Vitamin D is critical in preventing chronic metabolic syndromes including diabetes and cardiovascular disease (CVD) [4]. Vitamin D's active form (1.25-hydroxyvitamin D) causes an insulin response to glucose transport by promoting the formation of insulin receptors in peripheral tissues [5].
Vitamin $D$ and its metabolites are known to decrease blood lipid levels through lipogenesis. Vitamin D, on the other hand, enhances the activity of lipoprotein lipase in adipose tissue, resulting in a decrease in triglyceride-enriched lipoprotein in the blood, therefore decreasing the risk of developing CVD [6]. Vitamin D receptors identified in cardiac and vascular cells imply that Vitamin D-mediated activities contribute to the development of CVD [7]. Some clinical studies [4], [8] have discovered that Vitamin D has an effect on the lipid profile of diabetic patients. The objective of this study was to determine the relationship between blood Vitamin $D$ levels and risk factors in individuals with type 2 diabetes mellitus (T2DM).

\section{Materials and Methods}

\section{Research design}

This is an analytical study using a crosssectional design that was conducted in Medan. 


\section{Ethical approval}

The Research Ethics Committee at the University of North Sumatra in Indonesia approved this study (permission number: 280/KEP/USU/2020).

\section{Population and research samples}

The study population is composed of DMT2 people seeking treatments at Medan's main health care institutions. A sample size calculation for the oneproportion hypothesis resulted in a sample size of 89 participants. Consecutive sampling is used to choose samples, with inclusion and exclusion criteria in place. This study is intended to patients who see their primary care physician and are willing to participate in research. Patients with a history of vascular abnormalities before diabetes, a history of stroke, or a history of blood issues are not eligible to enroll.

\section{Laboratory examination}

After a $10 \mathrm{~h}$ fast, a venous blood test (up to $5 \mathrm{cc}$ ) is performed to determine the patient's Vitamin $D$ and lipid profile. Vitamin D levels are determined using the ELISA technique and a human ELISA Vitamin D kit (catalog: E1543Hu; Brand: Bioassay TL). Apo-A1 levels are determined using the ELISA method using a human ApoA1-ELISA kit (catalog: No E1535Hu; Brand: Bioassay TL). TC levels are determined using an enzymatic colorimetry approach (oxidase cholesterol method/CHOD PAP), whereas HDL-C, low-density lipoprotein cholesterol (LDL-C), and triglyceride levels are determined using the Group Policy Object-Trended method.

\section{Data analysis}

SPSS for Windows is used to assess the data, and the findings are presented in tables and graphs. The Shapiro-Wilk test ( $p>0.05)$ was used to determine the average normal distribution of sample data. The Pearson correlation test is used to determine the association between Vitamin D and CVD complication indicators in a bivariate analysis $(p<0.05)$.

\section{Results}

In this study, 89 people were chosen. The total patients observed encompassing the sex, age, and length of diabetes suffering may be seen more clearly in Table 1.

According to Table 2, the largest group of responders was 69 women $(77.5 \%)$. Diabetic patients have an average age of 55.2 years (SD \pm 8.9 ) and have diabetes for an average of 4.4 years $(S D \pm 4.3)$.
Table 1: The characteristics of 89 type 2 diabetes mellitus patients

\begin{tabular}{lll}
\hline Characteristics & Frequency $(\mathrm{n})$ & Percentage \\
\hline Sex & 20 & \\
$\quad$ Male & 69 & 22.5 \\
$\quad$ Female & $55.2(8.9)$ & 77.5 \\
Age, years (mean, SD) & $4.4(4.3)$ & \\
Duration of illness, (mean, SD) years & & \\
\hline
\end{tabular}

The average values of CVD compound parameters such as Apo-A1, TC, HDL-C, LDL-C, and triglyceride are shown in Table $2: 8.4 \mathrm{mg} / \mathrm{dl}, 220.1 \mathrm{mg} / \mathrm{dl}$, $46.7 \mathrm{mg} / \mathrm{dl}, 126.4 \mathrm{mg} / \mathrm{dl}$, and $244.4 \mathrm{mg} / \mathrm{dl}$, respectively. The Pearson correlation test indicated a relationship between Vitamin D levels and Apo-A1, TC, HDL-C, and triglyceride levels ( $p>0.05$ ). At the same time, there was no correlation $(p>0.05)$ between Vitamin $D$ levels and LDL-C levels.

Table 2: Correlation of Vitamin D with CVD risk parameters

\begin{tabular}{llllll}
\hline Parameter & Mean & SD & Min & Max & $\mathrm{p}$ \\
\hline Apo-A1(mg/dl) & 8,4 & 11.2 & 11.2 & 51.3 & 0.0001 \\
Total cholesterol (mg/dl) & 220.1 & 42.1 & 136 & 335 & 0.01 \\
HDL-C (mg/dl) & 46.7 & 11.7 & 24 & 77 & 0.001 \\
LDL-C (mg/dl) & 126.4 & 34.7 & 51 & 249 & 0,922 \\
Triglyceride (TG) & 244.4 & 124.0 & 11.2 & 51.3 & 0.034 \\
\hline LDL-C: Low-density lipoprotein cholesterol, HDL-C: High-density lipoprotein cholesterol.
\end{tabular}

\section{Discussion}

Vitamin $D$ levels were found to be associated with Apo-A1, TC, HDL-C, and triglycerides, all of which are associated with diabetic CVD complications [9], [10]. Diabetes causes an increase in the release of free fatty acids (FFA) from insulin-resistant lipid cells, increasing the risk of dyslipidemia [11]. Increased triglyceride synthesis results in increased apolipoprotein B (ApoB) and very low-density lipoprotein (VLDL) production. Apo-B and VLDL cholesterol levels are associated with an increased risk of heart disease. Hyperinsulinemia has been associated with decreased HDL and increased Apo-B and VLDL levels [12]. Hyperglycemia also has a detrimental effect on lipoproteins (particularly LDL and VLDL) by increasing glycosylation and oxidation, decreasing vascular compulsion, and actively encouraging the development of atherosclerosis [13].

According to Alkhatatbeh (2019), there is a favorable relationship between vitamin $D$ levels and HDL. High vitamin D levels raise HDL levels, lowering the risk of cardiovascular disease. The study, however, found that vitamin $D$ levels were unrelated to other lipid profiles such as LDL, triglycerides, and TC. They discovered a negative association between vitamin $D$ and $\mathrm{HbA} 1 \mathrm{C}$ levels in this study, and there is no relationship between vitamin $\mathrm{D}$ levels and blood sugar levels [14].

When renal impairment was included in people with T2DM, the connection between triglycerides, HDL$\mathrm{C}$, and cardiac events became negligible, indicating that kidney function plays a critical role in this interaction. 
Due to the fact that the kidney is the primary site of calcitriol activation to physiologically active calcitriol, it is also inextricably linked to Vitamin D status. Megalin and cubilin are required in the kidneys for the filtering of Vitamin D-DBP complexes, and renal failure results in Vitamin $D$ insufficiency as a result of urine loss and the prevention of future activation [15], [16]. Megalin is a member of the LDL receptor family that is specifically interested in lipoproteins containing Apo-B. Cubilin binds to Apo-A-I, which means that HDL is the ligand. Megalin and cubilin, as a result, are necessary for Vitamin D absorption and activation, as well as for the elimination of lipoprotein from circulation. Megalin expression is regulated by Vitamin $\mathrm{D}$. This association may aid in elucidating the possible mechanisms behind the relationship between Vitamin $D$ and blood lipid concentrations [17], [18].

When renal impairment was included in people with T2DM, the connection between triglycerides, HDL-C, and cardiac events was non-significant, indicating that kidney function plays a critical role in this interaction. Because the kidney is the primary site of calcitriol activation and conversion to physiologically active calcitriol, it is thus inextricably linked to Vitamin D status. Megalin and cubilin are necessary for the kidneys to filter Vitamin D-DBP complexes, and renal failure results in Vitamin $D$ insufficiency as a result of urine loss and the inhibition of future activation [15], [16]. Megalin is a member of the LDL receptor family that has a special affinity for lipoproteins carrying Apo-B. Because Apo-A-I is the ligand for cubilin, HDL is the ligand. As a result, megalin and cubilin are necessary for Vitamin D absorption and activation, as well as lipoprotein clearance from the circulation. Megalin expression is controlled by Vitamin $\mathrm{D}$. This association may aid in elucidating the possible mechanisms behind the relationship between Vitamin $D$ and blood lipid levels [17], [18].

Another potential mechanism for changes in lipid and vitamin $D$ levels is adiponectin. Adiponectin is a cytokine generated by adiposity with fat mass that has been shown to increase HDL levels while reducing VLDL and LDL concentrations. Adiponectin levels are connected to vitamin $\mathrm{D}$ levels, and dietary treatments to improve vitamin D status are associated to greater levels of adiponectin [19]. The presence of vitamin $D$ has also been related to vascular adhesion and endothelial dysfunction [20]. Obesity prevalence, fat mass count, adipose differentiation and proliferation, insulin secretion and sensitivity, blood pressure modulation, blood lipid changes, and atherogenesis inhibition are all factors that can contribute to the link between vitamin $D$ status and the risk of heart disease and death [21]. Vitamin D possesses anti-inflammatory properties that have been linked to its positive effects on a variety of inflammatory disease states, including diabetes and cardiovascular disease [22].

\section{Conclusion}

Vitamin D levels are associated with Apo-A1, TC, HDL cholesterol, and triglyceride levels, all of which are associated with CVD. Vitamin D supplements, as well as the patient's autonomous behavior in controlling blood sugar to minimize complications, notably CVD, which increase mortality and morbidity in T2DM, may be an alternative for reducing CVD issues in DMT2 patients.

\section{References}

1. Ama Moor VJ, Amougou SN, Ombotto S, Ntone F, Wouamba DE, Ngo Nonga B. Dyslipidemia in patients with a cardiovascular risk and disease at the University Teaching Hospital of Yaoundé, Cameroon. Int J Vasc Med. 2017;2017:6061306. http://doi. org/10.1155/2017/6061306

PMid:28163932

2. Závorková M, Vetvicka V, Richter J, Kral V, Liehnova I, Rajnohova DL. Effects of glucan and Vitamin D supplementation on obesity and lipid metabolism in diabetic retinopathy. Open Biochem J. 2018;12:36. http://doi.org/10.2174/1874091X01812010036 PMid:29760812

3. Jafari $\mathrm{T}$, Faghihimani $\mathrm{E}$, Feizi A, Iraj $\mathrm{B}$, Javanmard $\mathrm{SH}$, Esmaillzadeh A, et al. Effects of Vitamin D-fortified low fat yogurt on glycemic status, anthropometric indexes, inflammation, and bone turnover in diabetic postmenopausal women: A randomised controlled clinical trial. Clin Nutr. 2016;35(1):6776. http://doi.org/10.1016/j.clnu.2015.02.014

PMid:25794439

4. Harris SS. Does Vitamin D deficiency contribute to increased rates of cardiovascular disease and Type 2 diabetes in African Americans? Am J Clin Nutr. 2011;93(5):1175S-8.

5. Maestro B, Campión J, Dávila N, Calle C. Stimulation by 1 , 25-dihydroxyvitamin D3 of insulin receptor expression and insulin responsiveness for glucose transport in U-937 human promonocytic cells. Endocr J. 2000;47(4):383-91. http://doi. org/10.1507/endocrj.47.383

PMid:11075718

6. Potolitsyna NN, Bojko ER, Orr P. Lipid metabolism indices and their correlation with Vitamin $D$ levels in indigenous populations of northern European Russia. Human Physiol. 2011;37(2):66-70. PMid:21542320

7. Exebio J, Ajabshir S, Zarini G, Huffman F. The effect of Vitamin D supplementation on blood lipids in minorities with Type 2 diabetes. FASEB J. 2016;30:917-4.

8. Exebio JC, Ajabshir S, Campa A, Li T, Zarini GG, Huffman FG. The effect of Vitamin D supplementation on blood lipids in minorities with Type 2 diabetes. Int $\mathrm{J}$ Diabetes Clin Res. 2018;5(3):93

PMid:31497649

9. Amelia R, Harahap J, Lelo A, Wijaya $H$, Harahap NS Yamamoto Z. Risk analysis for cardiovascular complication based on the artherogenic index of plasma of Type 2 diabetes mellitus patients in Medan, Indonesia. Fam Med Prim Care Rev. 2020;22(3):197-201.

10. Amelia R, Harahap J, Wahyuni AS, Pratama A. Health Status of Elderly Based on Daily Activities Living, Cholesterol and Uric 
Acid Profile in Medan City. Vol. 125. In: IOP Conference Series: Earth and Environmental Science 2018 Mar 1. p. 012175.

11. Maki KC, Benes L, Dicklin MR. Pathophysiology and management of dyslipidemias associated with insulin-resistant states. In: Therapeutic Lipidology. Cham: Humana. 2021. p. 307-22.

12. Cruz-Bautista I, Mehta R, Cabiedes J, García-Ulloa C, GuillenPineda LE, Almeda-Valdés $P$, et al. Determinants of VLDL composition and apo B-containing particles in familial combined hyperlipidemia. Clin Chim Acta. 2015;438:160-5. PMid:25172037

13. Hamilton SJ, Watts GF. Endothelial dysfunction in diabetes: Pathogenesis, significance, and treatment. Rev Diabet Stud 2013;10:133.

14. Alkhatatbeh MJ, Amara NA, Abdul-Razzak KK. Association of 25-hydroxyvitamin D with HDL-cholesterol and other cardiovascular risk biomarkers in subjects with non-cardiac chest pain. Lipids Health Dis. 2019;18(1):27. http://doi. org/10.1186/s12944-019-0961-3 PMid:30684966

15. Amelia R, Sari D, Muzasti R, Fujiati I, Wijaya H. Early detection of diabetic nephropathy based on albumin creatinine ratio (ACR) in Type 2 diabetes mellitus patients in Medan Indonesia. Family Med Prim Care Rev. 2021;23(2):135-8. https://doi.org/10.5114/ fmpcr.2021.105903

16. Anderson RL, Ternes SB, Strand KA, Rowling MJ. Vitamin $D$ homeostasis is compromised due to increased urinary excretion of the 25-hydroxycholecalciferol-Vitamin D-binding protein complex in the Zucker diabetic fatty rat. Am J Physiol Endocrinol Metab. 2010;299(6):E959-67. http://doi.org/10.1152/ ajpendo.00218.2010

PMid:20876762

17. Larsen CP, Trivin-Avillach C, Coles P, Collins AB, Merchant M,
Ma H, et al. LDL receptor-related protein 2 (megalin) as a target antigen in human kidney anti-brush border antibody disease. J Am Soc Nephrol. 2018;29(2):644-53. http://doi.org/10.1681/ ASN.2017060664

PMid:29074737

18. Christensen El, Birn H. Megalin and cubilin: Multifunctional endocytic receptors. Nature reviews Mol Cell Biol. 2002;3(4):25867. http://doi.org/10.1038/nrm778

PMid: 11994745

19. Neyestani TR, Nikooyeh B, Alavi-Majd H, Shariatzadeh N, Kalayi A, Tayebinejad N, et al. Improvement of Vitamin D status via daily intake of fortified yogurt drink either with or without extra calcium ameliorates systemic inflammatory biomarkers, including adipokines, in the subjects with Type 2 diabetes. $\mathrm{J}$ Clin Endocrinol Metab. 2012;97(6):2005-11. http://doi.org/10.1210/ jc.2011-3465

PMid:22442277

20. Al Mheid I, Patel R, Murrow J, Morris A, Rahman A, Fike L, et al. Vitamin D status is associated with arterial stiffness and vascular dysfunction in healthy humans. J Am Coll Cardiol. 2011;58(2):186-92. http://doi.org/10.1016/j.jacc.2011.02.051 PMid:21718915

21. Jorde R, Grimnes G. Vitamin D and metabolic health with special reference to the effect of Vitamin $D$ on serum lipids. Prog Lipid Res. 2011;50(4):303-12. http://doi.org/10.1016/j. plipres.2011.05.001

PMid:21640757

22. Kestenbaum B, Katz R, de Boer I, Hoofnagle A, Sarnak MJ, Shlipak MG, et al. Vitamin D, parathyroid hormone, and cardiovascular events among older adults. J Am Coll Cardiol. 2011;58(14):1433-41. http://doi.org/10.1016/j.jacc.2011.03.069 PMid:21939825 